\title{
Dexamethasone Regulates Macrophage and Cd4+Cd25+ Cell Numbers in the Chicken Spleen
}

http://dx.doi.org/10.1590/18069061-2015-0035

quuthor(s)
Calefi AS'
Quinteiro-Filho WM'
Fukushima AR"
Cruz DSG da'
Siqueira A de"
Salvagni FA"
Namazu LB'
Gomes COMS'
Ferreira AJP'
Palermo Neto J'

Neuroimmunomodulation Research Group, Department of Pathology, School of Veterinary Medicine and Animal Science, University of São Paulo, São Paulo, Brazil.

" Department of Pathology, School of Veterinary Medicine and Animal Science, University of São Paulo, São Paulo, Brazil.

\section{ABSTRACT}

Dexamethasone (DEX) is a corticoid hormone that is experimentally used to mimic the effects of increased levels of endogenous corticosterone observed during the stress response. Currently, stress is considered one of the major predisposing factors for diseases in the poultry industry. The aim of this study was to analyze the effects of DEX and/or of a 20-fold coccidial vaccine dose on leukocyte phenotypes in the spleen and cecal tonsils of chickens. Twenty specific-pathogen-free (SPF) Leghorn chickens were divided into four groups: a non-treated group (NT), a DEX-treated group (Dex), a vaccinated group (V) and a DEX-treated+vaccinated group (Dex+V). On experimental day (ED) 42, each bird in the vaccinated groups received a anti-coccidial vaccine. DEX was injected in the birds of the Dex and Dex+V groups $(0.9 \mathrm{mg} / \mathrm{kg})$ onED42 and ED45. The immunophenotyping was performed by flow cytometry analysis of splenocytes and cecal tonsils cells onED48. DEX treatment per se was unable to change $\mathrm{CD}^{+}{ }^{+} \mathrm{CD} 8^{+}, \mathrm{CD} 4^{+} \mathrm{CD} 8^{+}$and $\mathrm{CD} 4$ $\mathrm{CD} 8^{+}$populations with $\mathrm{TCR} \gamma \delta$ or $\mathrm{CD} 28$ in the spleen, or macrophages and $T$ lymphocytes in the cecal tonsils. $V$ group birds presented higher numbers of splenic macrophages compared with those measured in the Dex $+V$ group. The number of $C D 4+C D 25^{+}$cells in the spleen of birds of the $V$ group was higher than those measured in the other experimental groups. Our data suggest that $\mathrm{CD} 4{ }^{+} \mathrm{CD} 25^{+}$cells and macrophages might be influenced by DEX treatment in spleen, but not in the cecal tonsils of chickens inoculated with Eimeria.

\section{INTRODUCTION}

Dexamethasone (DEX) is an immunosuppressant drug that is widely used to study some stressor effects in disease development and course in poultry (Huff et al., 2001, 2013; Shini et al., 2010). Given its similarity to endogenous corticosteroids, DEX treatment is thought to reproduce the effects of high levels of corticosterone, thus mimicking stressassociated signaling pathways (Devenport et al., 1989).

DEX treatment of chickens infected with Eimeria mivatiwas reported to reduce the $\mathrm{CD} 8^{+}, \mathrm{TCR} \gamma \delta$ and $\mathrm{MHC}-\mathrm{Il}^{+}$cells and to increase in the $\mathrm{CD}^{+}$and $\mathrm{CD}^{+}$cells in their spleen; these findings were followed by a reduction in lymphocyte activity, which was related to the reported increase in E. mivati infection (Isobe \& Lillehoj, 1993).

Coccidial infection induces complex immune responses. Different strains of Eimeria are known to produce variable immune responses under natural conditions (Lillehoj \& Trout, 1996). The determination of the immunomodulatory effects of drugs such as DEX, which mimics an increase in endogenous corticosteroid levels, may aid the understanding the course of coccidiosis infection and vaccination failures during stress. 
Calefi AS, Quinteiro-Filho WM, Fukushima AR, Cruz DSG da,

Siqueira A de, Salvagni FA, Namazu LB,

Gomes COMS, Ferreira AJP, Palermo Neto J
Dexamethasone Regulates Macrophage and Cd4+Cd25+ Cell Numbers in the Chicken Spleen
Recent biotechnological developments have contributed for the characterization of novel phenotypes of avian immune cells (Kaiser, 2010). A better understanding of certain cells populations activities, such as regulatory $T$ lymphocytes (i.e., regulatory $C D 4{ }^{+} C D 25^{+}$cells) may open new avenues to ascertain poultry's immune responses to infectious agents (Shanmugasundaram \& Selvaraj, 2011, 2012a, 2012b; Selvaraj, 2013). Studies in the field of neuroimmunomodulation are showing that these lymphocyte populations and mainly the resident cells present in lymphoid organs, such as those of the spleen and cecal tonsils, play relevant and definitive roles in the course of infectious diseases (Shanmugasundaram \& Selvaraj, 2011, 2012a, 2012b; Selvaraj, 2013).

The aim of this study was to analyze the effects of a DEX treatment and/or a coccidial overdose vaccination on B and T lymphocytes and macrophages phenotypes in the spleen and cecal tonsils of chickens.

\section{MATERIALS AND METHODS}

\section{Birds}

Twenty specific-pathogen-free (SPF) male Leghorn chickens were housed in isolation chambers (Alesco, São Paulo, Brazil) with a maximum density of 10 animals per square meter from the first day posthatching. The chickens received water and feed ad libitum with no additives, as these may intervene with the development of the inoculated Eimeria. The light/dark cycle was 12/12 h, with lights on at 7:00 a.m. The experimental protocol was approved by the Committee on the Care and Use of Laboratory Animal Resources, School of Veterinary Medicine and Animal Science, University of São Paulo, Brazil (\# 3071/2013).

\section{Experimental groups and treatments}

On experimental day 1 (ED1), the 20 chickens were randomly allocated in four groups: a non-treated group (NT, n=5), a DEX-treated group (Dex, n=5), an Eimeria spp.-vaccinated group $(\mathrm{V}, \mathrm{n}=5)$ and a DEX-treated + Eimeria spp.-vaccinated group (Dex $+\mathrm{V}, \mathrm{n}=5$ ).

\section{Coccidiosis overdose vaccination}

ON ED42, birds were vaccinated (Coccivac-D, MSD Animal Health, NJ, USA) by gavage at a concentration twenty-fold higher than the manufacturer's recommendations (groups $\mathrm{V}$ and Dex $+\mathrm{V}$ ). This dose was chosen to challenge the intestinal integrity as reported elsewhere for experimental necrotic enteritis induction (Lee et al., 2011). The vaccine used contains live oocysts of precocious strains of Eimeria acervulina, E. brunetti ,E. hagani, E. tenella, E. necatrix, E. mivati, E. maxima, and E. praecox.

\section{DEX treatment}

The birds in the Dex and Dex+V groups were injected with DEX (D4092, Sigma-Aldrich, MO, USA) via the intracoelomic route (dose $=0.9 \mathrm{mg} / \mathrm{kg}$ ) on ED42 and ED45.

The birds of the NT group did not receive any treatment and remained undisturbed in their home chamber till the time of analysis.

\section{Antibodies}

The primary monoclonal antibodies used in this study are shown in Table 1. The antibodies used to detect macrophages and antigen-presenting cells were as follows: mouse anti-chicken monocytes/ macrophages, clone KUL01; mouse anti-chicken CD80, clone IAH:F864:DC; mouse anti-chicken CD86, clone IAH:F853:AG2; and mouse anti-chicken $\mathrm{MHC}$ class II, clone 2G11. The antibodies used to detect lymphocytes were as follows: human antichicken CD25, clone 13504; mouse anti-chicken CD3, clone CT-3; mouse anti-chicken TCR $\gamma \delta$, clone TCR-1; mouse anti-chicken CD45, clone LT40; mouse anti-chicken CD8 $\alpha$, clone CT-8; mouse anti-chicken CD28, clone AV7; mouse anti-chicken CD4, clone CT4; and mouse anti-chicken Bu-1, clone AV20. Mouse $\lg \mathrm{G} 1$ isotype controls conjugated to Fluorescein (FITC), R-phycoerythrin (R-PE), R-phycoerythrin-Texas Red (Texas Red), Allophycocyanin (APC), Spectral Red (SPRD), Cyanine 5 (Cy5) or Alexa Fluor 647 (Alexa 647) were used as fluorescence controls. Streptavidinconjugated APCs were used to label biotinylated primary antibodies (Table 1). Anti-mouse antibodies conjugated with Texas Red were used as secondary antibodies to detect unlabeled antibodies (Table 1). Anti-CD80, CD86 and CD25 cell marker antibodies were purchased from AbD Serotec (USA), and the other cell markers were purchased from Southern Biotech (AL, USA).

\section{Immunophenotyping of splenic and cecal tonsil leukocytes}

On ED48, the spleen and cecal tonsils were collected in conical tubes containing $4 \mathrm{~mL}$ of RPMI 1640 (SigmaAldrich, MO, USA). The tissues were cut into sections of approximately $1 \mathrm{~mm}^{3}$. The cells were subsequently gently disrupted with the aid of a syringe plunger. 
Table 1 - Identification of cell markers used for immunophenotyping of spleen and/or cecal tonsil cells along with their specificity and the conjugate/labels used for detection.

\begin{tabular}{|c|c|c|}
\hline Cell surface antigens & Specificity & Conjugate/labels \\
\hline Macrophage/Monocyte ${ }^{a}$ & Chicken monocytes and macrophages & $\mathrm{R}-\mathrm{PE}$ \\
\hline MHC Class $\|^{b}$ & $\begin{array}{l}\text { Antigen-presenting cells, including activated B cells, activated T cells, macrophages and } \\
\text { dendritic cells }\end{array}$ & R-PE or FITC \\
\hline CD80 & $\begin{array}{l}\text { Antigen-presenting cells, including activated B cells, activated T cells, macrophages and } \\
\text { dendritic cells }\end{array}$ & Unlabeled-Texas Red \\
\hline$C D 86^{d}$ & $\begin{array}{l}\text { Antigen-presenting cells, including activated B cells, activated T cells, macrophages and } \\
\text { dendritic cells }\end{array}$ & Unlabeled-Texas Red \\
\hline CD3e & T cells & SPRD \\
\hline $\mathrm{CD}^{\prime} 5^{f}$ & Leukocytes & APC \\
\hline $\operatorname{CD} 8 \alpha^{9}$ & Cytotoxic T cells & Cy5 \\
\hline$C D 4^{h}$ & T helper cells & CD4 \\
\hline $\mathrm{Bu}-1^{\mathrm{i}}$ & B cells & Alexa 647 \\
\hline CD25 & $\begin{array}{l}\text { IL-2 receptor alpha chain } \\
\text { in } \mathrm{T} \text { cells }\end{array}$ & FITC \\
\hline $\mathrm{CD} 28^{\mathrm{k}}$ & T cells except TCR $\gamma \delta$ lymphocytes & Biotin-streptavidin-APC \\
\hline TCR $\gamma \delta^{\prime}$ & TCR $\gamma \delta$ lymphocytes & FITC \\
\hline
\end{tabular}

Notes: Alexa 647 - Alexa Fluor 647; APC - Allophycocyanin; Cy5 - Cyanine 5; FITC - Fluorescein isothiocyanate; R-PE - R-Phycoerythrin; Texas Red - R-Phycoerythrin-Texas Red;

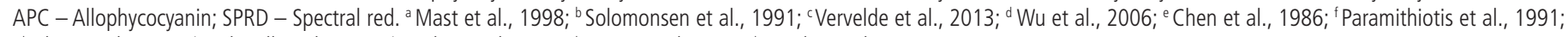
g.h Chan et al., 1988; ' Rothwell et al., 1996; ' Neulen et al., 2015; ' Young et al., 1994; 'Sowder et al., 1988.

The contents were transferred to a polystyrene tube coupled with a cell strainer (Becton Dickinson, NJ, USA) with a $0.7 \mu \mathrm{m}$-pore mesh. Leukocytes were counted in a Neubauer chamber using trypan blue for exclusion of the dead cells to determine the number of viable leukocytes.

Splenic leukocytes ( $1 \times 10^{6}$ cells) were submitted to red blood cell lysis via the addition of $2 \mathrm{~mL}$ of FACS lysis buffer (Becton Dickinson, NJ, USA) for 5 min at $37^{\circ} \mathrm{C}$. This procedure was not performed on cecal tonsil cells.

Each sample analyzed comprised $1 \times 10^{6}$ cells per cytometer tube (spleen and cecal tonsil cells). Single staining was performed using the antibodies described above diluted at 1 to $3 \mu \mathrm{g}$ in $100 \mu \mathrm{L}$ of PBS (pH 7.4). The suspensions of cells with antibodies were kept at $4^{\circ} \mathrm{C}$ for $45 \mathrm{~min}$ in the dark. After the incubation period, the cells were washed once with $2 \mathrm{~mL}$ of PBS and centrifuged at $400 \times \mathrm{g}$ for $8 \mathrm{~min}$. The cells were then resuspended in $100 \mu \mathrm{L}$ of PBS for fluorescence measurement by flow cytometry or subjected to secondary antibody labeling. Unlabeled antibodies and biotin-conjugated antibodies were incubated with secondary anti-mouse antibodies conjugated with Texas Red and streptavidin-APC conjugates, respectively, at $4^{\circ} \mathrm{C}$ for $45 \mathrm{~min}$ in the dark. After the incubation period, the cells were washed once with $2 \mathrm{~mL}$ of PBS and centrifuged at $400 \times \mathrm{g}$ for $8 \mathrm{~min}$. The cells were then resuspended in $100 \mu \mathrm{L}$ of PBS for fluorescence measurement by flow cytometry.

Multiple staining was performed to assess macrophages/monocytes and $\mathrm{T}$ cell subsets. The populations analyzed in the cecal tonsils were CD45/CD3， CD45/TCR $\gamma /$ /CD8 $\alpha / C D 4$, monocyte/ macrophage/MHCII, and Bu-1. The populations analyzed in the spleen were CD45/CD3, CD45/TCR $\gamma \delta /$ CD8 $\alpha / C D 4, B u-1, C D 4 / C D 8 / C D 25, C D 4 / C D 8 / C D 28$, monocyte/macrophage/ MHCI//CD80 and CD86.

Measurements were performed using a BD FACSCalibur (BD Biosciences CA, USA) flow cytometer. This flow cytometer was equipped with a 488-nm (blue) laser allowing the detection of three colors (530/30, 575/26 and 650 LP [long pass] filters) and a $635-\mathrm{nm}$ (red) laser that enabled single-color detection (670 LP [long pass] filter). A total of 10,000 measurements were performed for each sample. All antibodies were titrated prior to the experiment to determine the optimal staining concentrations, and a multicolor panel was evaluated using fluorescenceminus-one (FMO) controls and isotype controls for each fluorophore. The analyses were performed using the software FlowJo v10.0.7 (FlowJo, OR, USA).

\section{Statistical analysis}

Statistical analysis was performed using GraphPad Prism (GraphPad 6 Software Inc., CA, USA). The data were analyzed using one-way analysis of 
variance (ANOVA) followed by the Tukey-Kramer test for multiple comparisons. The probability of $p<0.05$ was taken as showing statistical significant differences among the data. Results are presented as means $\pm S D$.

\section{RESULTS}

\section{Immunophenotyping of lymphocytes and macrophages in the cecal tonsils}

Eimeria vaccination (V group) and DEX injection (DEX group) per se were unable to change the number of CD45 cells among the different groups (mean number of positive cells measured $=60.80 \pm 10.20 \%$, data not shown). Similarly, there were no significant differences in the numbers of $\mathrm{CD}^{+}$cells among the groups (mean number of positive cells of $36.80 \pm 8.22 \%$, data not shown). Similarly, significant differences were not found between birds of the Dex+V and $V$ groups for the number of $T$ cells $\left(C D 4^{+} \mathrm{CD}^{+}, \mathrm{CD} 4^{+} \mathrm{CD} 8\right.$, or $\mathrm{CD} 4 \mathrm{CD}^{+}$, with or without the presence of $\left.\mathrm{TCR} \gamma \delta\right), \mathrm{B}$ lymphocytes $\left(\mathrm{Bu}-1^{+}\right)$, and for macrophages in the cecal tonsils (data not shown).

\section{Immunophenotyping of macrophages in the chicken spleen}

The birds inoculated with precocious strains of coccidia ( $V$ group) showed a significant increase $(p<0.05)$ in the number of splenic macrophages in relation to those measured in the non-treated birds (NT group); however, this increase was not significantly different from the data observed in the birds of the Dex group ( $p>0.05$; Figure 1). However, the DEX treatment of the birds vaccinated with the Eimeria spp. strains (Dex+V group) abrogated the increase in the number of splenic macrophages found in the vaccinated animals ( $V$ group; $p<0.05$; Figure $1 \mathrm{~A}$ ).

Significant differences were also not observed in the mean fluorescence intensity (MFI) of $\mathrm{MHC}-\mathrm{II}^{+}$expression in splenic macrophages; however, a tendency towards an increase of $\mathrm{MHC}-\mathrm{II}^{+}$expression was observed in the coccidia-vaccinated birds ( $V$ group; $p>0.05$; Figure $1 \mathrm{~b})$. This trend was not observed in the DEX-treated vaccinated birds (Dex $+V$ group; Figure $1 \mathrm{~B}$ ) compared with the birds of both NT and DEX groups.

Finally, significant differences were not found in the number of splenic $\mathrm{CD} 80^{+}$or $\mathrm{CD} 86^{+}$macrophages among the four groups.

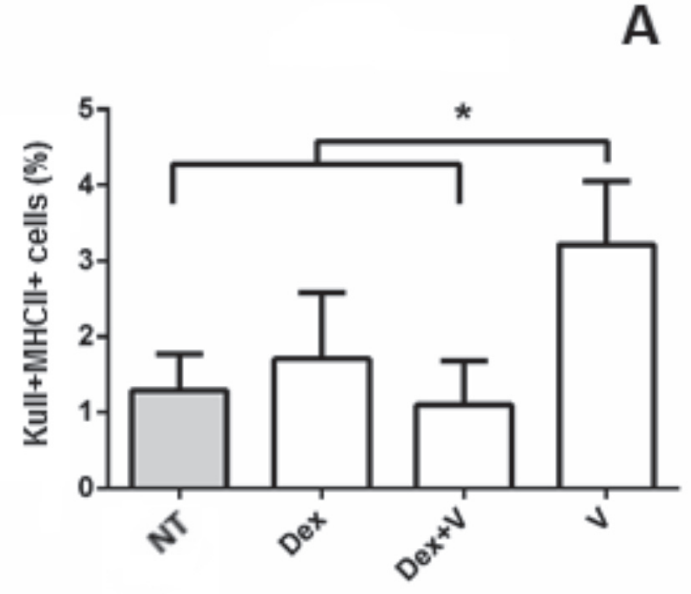

B

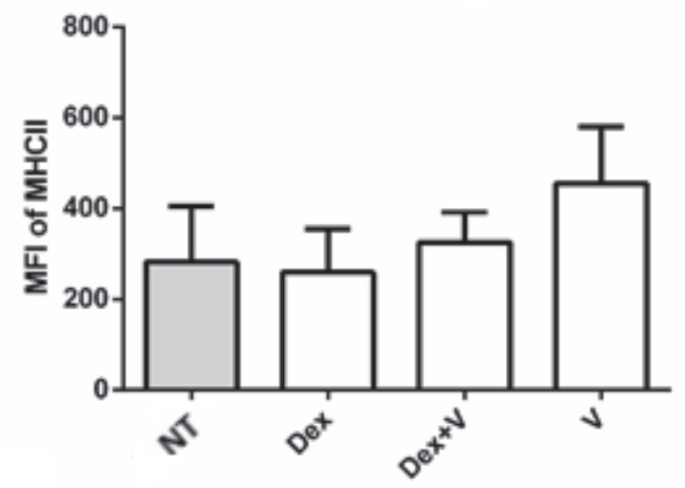

Figure 1. Splenic immunophenotyping of macrophages (Kull+MHCll+ cells) (A) and of $\mathrm{MHC}$ class II fluorescence intensity per Kull+ cells (B). An asterisk on top of columns means a statistically significant differences at $p<0.05$ (one-way ANOVA and Tukey test for multiple comparisons). Data are mean \pm SD of 5 birds per group. NT - Non-treated group; Dex - DEX-treated group; Dex+V - DEX-treated + Eimeria spp.-infected group;V - Eimeria spp.-infected group; MFI - mean fluorescence intensity.

\section{Immunophenotyping of lymphocytes in the chicken spleen}

Lysis of erythrocytes from the spleen cell suspension produced an average of $95.71 \pm 3.48 \%$ CD $45^{+}$cells. Approximately $63.07 \pm 10.22 \%$ of these cells were $\mathrm{CD}^{+}$lymphocytes. Significant differences were not observed in the populations of $\mathrm{T}$ lymphocytes $\left(\mathrm{CD}^{+}\right.$, $\mathrm{CD}^{+}{ }^{+} \mathrm{CD} 8^{+}, \mathrm{CD}^{+} \mathrm{CD} 8$, or $\mathrm{CD} 4{ }^{-} \mathrm{CD} 8^{+}$, with or without the presence of TCR $\gamma \delta$ or CD28) or B lymphocytes (Bu$\left.1^{+}\right)$(data not shown).

The Eimeria spp. vaccinated birds ( $\mathrm{V}$ group) presented an increased number of $\mathrm{CD} 4{ }^{+} \mathrm{CD} 25^{+}$cells in relation to those determined in the vaccinated birds that received the DEX treatment ( $D e x+V$ group; $p<0.05$; Figure 2) and also to the uninfected birds (NT and DEX groups; $p<0.05$; Figure 2). Significant differences were not found among the numbers of CD4+CD25+ cells in birds of the NT, Dex and Dex+V groups (Figure 2). 


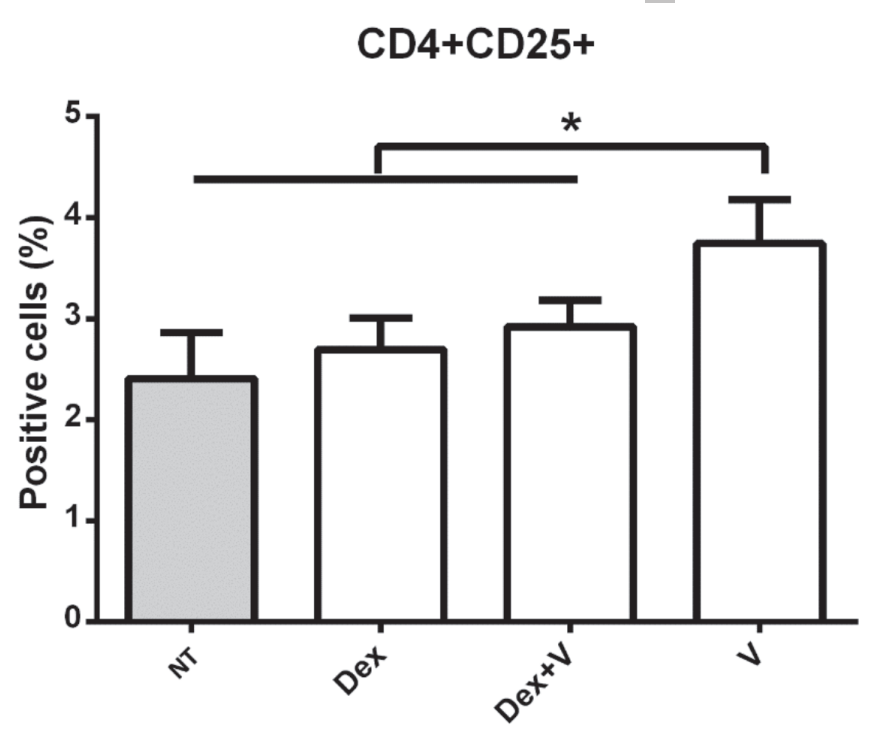

Figure 2. Number ofsplenic CD4+CD25+ lymphocytes. An asterisk on top of columns means a statistically significant differences at $p<0.05$ (one-way ANOVA and Tukey test for multiple comparisons). Data are mean \pm SD of 5 birds per group. NT - Non-treated group; Dex - DEX-treated group; Dex+V - DEX-treated +Eimeria spp.-infected group;V - Eimeria spp.-infected group.

\section{DISCUSSION}

DEX has been used to induce immunosuppression in birds, thus mimicking a stress response (Shini et al., 2010). In literature, DEX has been employed as an experimental model of stress effects on various diseases, such as clostridial dermatitis (Huff et al., 2013). These studies have inferred that the immunomodulatory effects of DEX somehow mimic those commonly induced by stressors, i.e., they may similarly trigger the development or modify the course of poultry diseases (Huff et al., 2013; Shini et al., 2010). Although DEX has been used to analyze the development of avian diseases (Puvadolpirod and Thaxton, 2000; Huff et al., 2005; Li et al., 2009), little is known on its immunomodulatory effects during host-pathogen interactions, such as those that occur in animals with coccidiosis.

Isobe and Lillehoj (1993) demonstrated that treatment of chickenswith DEX suppressed the T-cell response in the spleen and increased the birds' susceptibility to E. mivati infection. In fact, that study showed that the treatment with DEX increased the subpopulations of $\mathrm{CD}^{+}$splenic lymphocytes, simultaneously decreasing the production of IFN- $\gamma$ and IL-2 cytokines (Isobe \& Lillehoj, 1993). Therefore, it is possible that reduced cytokine production, such as IFN- $\gamma$, may be related to the decreased level of splenic macrophage activation observed in the present study (Figure 1A) (Bashyam, 2007). In turn, this decrease may have induced the trend of a reduction of the expression of MHC class II (Figure 1B), which ma be causally related to the observed reduction in macrophages' antigen recognition capability.

The observed decrease in MHC class II expression among macrophages seem to be related to an increase in regulatory T-cell activity, specifically of $\mathrm{CD}^{+} \mathrm{CD} 25^{+}$ cells (Tiemessen et al., 2007). The suppression of this lymphocyte may have induced a reduction in the level of cytokine expression (i.e., IFN- $\gamma$ ) in the birds of the present study, resulting in the effects here reported. In our study, the population of lymphocytes (CD4+CD25+) was lowerin Eimeria-inoculated birds treated with DEX compared with those vaccinated (i.e., between Dex+V $x \vee$ groups). The reduction in number of these cells may have triggered the release of small amounts of $\mathrm{IL}-10$, a cytokine that is known to inhibit macrophage responses (Shanmugasundaram \& Selvaraj, 2011). In this context, an abrogation of regulatory T lymphocytes is consistent with data reported elsewhere for lymphocyte proliferation (Shanmugasundaram \& Selvaraj, 2011).

Birds that were vaccinated with coccidia only (V group) presented high numbers of macrophages and CD4 ${ }^{+}$CD $25^{+}$cells in the spleen, i.e., Eimeria inoculation per se may have induced the proliferation and/or migration of these cell populations to the spleen. As coccidial infection per se did not reduce the numbers of immune cells, it is possible to infer that the $C D 4^{+} \mathrm{CD} 25^{+}$ cell population is, in fact, a subpopulation of cells composed mainly by activated $\mathrm{CD}^{+}{ }^{+} \mathrm{T}$ lymphocytes, i.e., the response to Eimeria inoculation per se and not a subpopulation of cells that induces the suppression of T lymphocyte proliferation. It should noted, however, that simple immunophenotypic characterization of $\mathrm{CD}^{+}{ }^{+} \mathrm{CD} 25^{+}$cells is not enough to determine whether these cells belong to the immunosuppressive lymphocyte population. Thus, it seems reasonable to suggest that the population of $\mathrm{CD} 4{ }^{+} \mathrm{CD} 25^{+}$cells found in our study may include a range of lymphocyte subsets with distinct activities, especially because CD25 is part of the IL-2 receptor (Teng et al., 2006). Moreover, splenic memory $T$ cells constitutively express the CD25 marker (Reinhardt et al., 2012). Thus, in spite of the small number of birds per group used in the current experiment, our data strongly point towards a corticoid effect on memory $T$ cells formation in the spleen, thus suppressing the immune response triggered by the infectious challenge. Future experiments might ascertain this hypothesis.

An important aspect of the use of DEX in our experimental model is that the drug reduced the 
numbers of macrophages and $\mathrm{CD} 4^{+} \mathrm{CD} 25^{+}$cells and did not substantially affect other cell subsets (CD3', $\mathrm{CD}^{+}{ }^{+} \mathrm{CD} 8^{+}, \mathrm{CD}_{4}{ }^{+} \mathrm{CD} 8$, and $\mathrm{CD} 4{ }^{-} \mathrm{CD}^{+}{ }^{+}$combined with $\mathrm{TCR} \gamma \delta$ or CD28). Furthermore, it is noteworthy from our study that the effects of DEX treatment on macrophages was mainly observed in the splenic population; indeed, significant changes were not detected in the birds'cecal tonsils. The anti-inflammatory effects exerted by exogenous corticoids such as DEX on the intestinal mucosa, a fact that is known to reduce macrophage activation and migration, could tentatively explain these results.

In summary, our work showed that $\mathrm{CD} 4{ }^{+} \mathrm{CD} 25^{+}$cells and splenic macrophages are strongly influenced by DEX treatment. However, DEX treatment was unable to modify the $\mathrm{CD}^{+}, \mathrm{CD}^{+}{ }^{+} \mathrm{CD} 8^{+}, \mathrm{CD} 4^{+} \mathrm{CD} 8$, and $\mathrm{CD} 4{ }^{-}$ $\mathrm{CD}^{+}$populations with $\mathrm{TCR} \gamma \delta$ or $\mathrm{CD} 28$ within the spleen or the macrophage and $C D 4^{+} \mathrm{CD} 8^{+}, \mathrm{CD} 4^{+} \mathrm{CD} 8$, and CD4-CD8+ populations with TCR $\gamma \delta$ within the cecal tonsils.

\section{ACKNOWLEDGMENTS}

This study was supported by FAPESP Foundation (Processes 2009/51886-3, 2012/03103-2 and 2013/17408-2) and by CNPq (Processes 474690/2013-

$0)$ to whom the authors wish to express their gratitude.

\section{REFERENCES}

Chan MM, Chen CL, Ager LL, Cooper MD. Identification of the avian homologues of mammalian CD4 and CD8 antigens. The Journal of Immunology 1988;140(7):2133-2138.

Chen CL, Ager LL, Gartland GL, Cooper MD. Identification of a $T 3 / T$ cell receptor complex in chickens. The Journal of experimental medicine 1986;164(1):375-380.

Devenport L, Knehans A, Sundstrom A, Thomas T. Corticosterone's dual metabolic actions. Life Sciences 1989:45(15):1389-1396.

Hong YH, Lillehoj HS, Lillehoj EP, Lee SH. Changes in immune-related gene expression and intestinal lymphocyte subpopulations following Eimeria maxima infection of chickens. Veterinary Immunology and. Immunopathology 2006;114(3):259-272.

Huff GR, Huff WE, Balog JM, Rath NC. Effect of early handling of turkey poults on later responses to a dexamethasone - Escherichia coli challenge. 1. production values and physiological response. Poultry Science 2001;80(9):1305-1313.

Huff GR, Huff WE, Balog JM, Rath NC, Anthony NB, Nestor KE. Stress response differences and disease susceptibility reflected by heterophil to lymphocyte ratio in turkeys selected for increased body weight. Poultry Science 2005;84(5):709-717

Huff GR, Huff WE, Rath NC. Dexamethasone Immunosuppression Resulting in Turkey Clostridial Dermatitis: A Retrospective Analysis of Seven Studies, 1998-2009. Avian Disease 2013;57(4):730-736.
Isobe, T, Lillehoj HS. Dexamethasone suppresses T cell-mediated immunity and enhances disease susceptibility to Eimeria mivati infection. Veterinary Immunology and Immunopathology 1993;39(4):431-446.

Kaiser, P. Adances in avian immunology-prospects for disease control: a review. Avian Pathology 2010;39(5):309-324.

Lee SH, Lillehoj HS, Jang SI, Baldwin C, Tompkins D, Wagner B, et al. Development and characterization of mouse monoclonal antibodies reactive with chicken interleukin-2 receptor alpha chain (CD25). Veterinary Immunology and Immunopathology 2011;144(3):396-404.

Lee KW, Lillehoj HS, Jeong W, Jeoung HY, An DJ. Avian necrotic enteritis: experimental models, host immunity, pathogenesis, risk factors, and vaccine development. Poultry Science 2011;90(7):1381-1390.

Li Y, Cai HY, Liu GH, Dong XL, Chang WH, Zhang S, et al. Effects of stress simulated by dexamethasone on jejunal glucose transport in broilers. Poultry Science 2009;88(2):330-337.

Lillehoj HS, Min W, Dalloul RA. Recent progress on the cytokine regulation of intestinal immune responses to Eimeria. Poultry Science 2004;83(4):611-623.

Lillehoj $\mathrm{H}$, Trout J. Avian gut-associated lymphoid tissues and intestinal immune responses to Eimeria parasites. Clinical Microbiology 1996:9(4):349-360.

Mast J, Goddeeris BM, Peeters K, Vandesande F, Berghman LR Characterisation of chicken monocytes, macrophages and interdigitating cells by the monoclonal antibody KUL01. Veterinary immunology and immunopathology 1998;61(2):343-357.

Neulen ML, Viertlboeck BC, Straub C, Göbel TW. Identification of novel chicken CD4+ CD3- blood population with NK cell like features. Developmental \& Comparative Immunology 2015;49(1):72-78

Paramithiotis E, Tkalec L, Ratcliffe MJ. High levels of CD45 are coordinately expressed with CD4 and CD8 on avian thymocytes. The Journal of Immunology 1991;147(11):3710-3717.

Puvadolpirod S, Thaxton JP. Model of physiological stress in chickens 1. Response parameters. Poultry Science 2000;79(3):363-369.

Rothwell CJ, Vervelde L, Davison TF. Identification of chicken Bu-1 alloantigens using the monoclonal antibody AV20. Veterinary immunology and immunopathology 1996;55(1):225-234.

Salomonsen J, Dunon D, Skjødt K, Thorpe D, Vainio O, Kaufman J. Chicken major histocompatibility complex-encoded BG antigens are found on many cell types that are important for the immune system. Proceedings of the National Academy of Sciences 1991;88(4):1359-1363.

Selvaraj RK. Avian CD4(+)CD25(+) regulatory T cells: properties and therapeutic applications. Developmental Comparative Pathology 2013;141(3):397-402.

Shanmugasundaram, R, Selvaraj, RK. Regulatory T cell properties of chicken CD4+CD25+ cells. Journal of Immunology 2011;186(4):1997-2002.

Shanmugasundaram, R, Selvaraj, RK CD4+CD25+ Regulatory T cell ontogeny and preferential migration to the cecal tonsils in chickens. PloS One 2012a;7(3):e33970

Shanmugasundaram R, Selvaraj RK. Regulatory $T$ cell properties of thymic CD4+CD25+ cells in ducks. Veterinary Immunology and Immunopathology 2012B;149(1-2):20-27.

Shanmugasundaram R, Selvaraj RK. In ovo injection of anti-chicken CD25 monoclonal antibodies depletes CD4+CD25+ T cells in chickens. Poultry Science 2013;92(1):138-142. 
Shini S, Huff GR, Shini A, Kaiser P. Understanding stress-induced immunosuppression: exploration of cytokine and chemokine gene profiles in chicken peripheral leukocytes. Poultry Science 2010;89(4):841-851

Sowder JT, Chen CL, Ager LL, Chan MM, Cooper MD. A large subpopulation of avian T cells express a homologue of the mammalian T gamma/delta receptor. The Journal of experimental medicine 1988;167(2):315-322.

Taams, LS, van Amelsfort JMR, Tiemessen MM, Jacobs KMG, de Jong EC, Akbar AN, Bijlsma JWJ, Lafeber FPJG. Modulation of monocyte/ macrophage function by human $C D 4+C D 25+$ regulatory $T$ cells. Human Immunology 2005;66(3):222-230

Teng QY, Zhou JY, Wu JJ, Guo JQ, Shen HG. Characterization of chicken interleukin 2 receptor alpha chain, a homolog to mammalian CD25. FEBS Letters 2006;580(17):4274-4281.
Tiemessen $M M$, Jagger $A L$, Evans $H G$, van Herwijnen MJC, John $S$, Taams LS. CD4+CD25+Foxp3+ regulatory $T$ cells induce alternative activation of human monocytes/macrophages. Proceedings of the National Academy of Sciences of the United States of America 2007;104(49):19446-19451.

Vervelde L, Reemers SS, van Haarlem DA, Post J, Claassen E, Rebel JM et al. Chicken dendritic cells are susceptible to highly pathogenic avian influenza viruses which induce strong cytokine responses. Developmental \& Comparative Immunology 2013;39(3):198-206.

Wu Z, Rothwell L, Young JR, Kaufman J, Butter C, Kaiser P. Generation and characterization of chicken bone marrow-derived dendritic cells. Immunology 2010;129(1):133-145.

Young, JR, Davison TF, Tregaskes CA, Rennie MC, Vainio O. Monomeric homologue of mammalian CD28 is expressed on chicken T cells. The Journal of Immunology 1994;152(8):3848-3851. 
